\title{
The History Wars of Economics: The Classification Struggle in the History of Economic Thought
}

\author{
Steven Kates* and Alex Millmow**1
}

\section{$1 \quad$ Introduction}

The study of the history of economics in Australia has just gone through an existential struggle of the greatest significance. On the surface it was only the most trivial of matters, a proposed clerical change in the classification of the History of Economic Thought by the Australian Bureau of Statistics (ABS). But, insignificant as it might at first appear, it was a proposal that had the potential to all but eliminate the history of economics as a legitimate academic study within Australia.

The core issue was whether History of Economic Thought and Economic History were to be included as sub-disciplines of economics within the ABS classification system. The ABS proposal was that both groups were to be placed in an entirely separate category under the heading, 'History, Archaeology, Religion and Philosophy'. Neither would any longer be classified in any way as belonging to the study of economics. It was this proposal that commenced a short but ultimately successful campaign to have both areas retain their position within the economics classification.

But, short as it was, and as narrow as the issues might seemingly be, into this campaign was brought a national and international array of economists which included presidents of international societies in the history of economic thought, economists from throughout the upper levels of the public service in Australia, historians of economics from across the world and which even included the strong views of the 2006 Nobel prize winner in economic theory.

There were many lessons learned during this clash, which this article will review. But the first of the lessons was this: that trouble can come out of the clearest blue skies and arrive from nowhere without the least expectation that anything is amiss with the world at large.

It was the following letter sent out by the ABS and distributed by John Lodewijks to HETSA members ${ }^{2}$ on 28 August 2007 that touched off the events that followed. By the time the letter was distributed, only around two weeks were available to organise a response. This is the letter that was distributed, announcing that HET and EH were to be reclassified.

\section{Dear Colleague}

The Australian Bureau of Statistics (ABS) is revising Research Fields, Courses and Disciplines (RFCDs) and is consulting on the proposed changes [which were included in an attached spreadsheet]....

Feedback is needed by Weds 12th September.

\section{What's changed?}

The overall structure and composition of the ASRC 1998 [Australian Standard Research Classifications] is largely retained in the revision. The 
term Research Fields, Courses and Disciplines (RFCD) is replaced with a new simpler term Field of Research (FOR); the term socioeconomic objective (SEO) is retained without change....

If you wish to suggest any changes, please bear in mind that the FOR is a process classification; that is, $R \& D$ is categorised by the processes and techniques used, whereas the SEO is a purpose classification, where $R \& D$ is categorised by the processes, areas and activities which the research aims to improve.

Likewise, the ASRC is not intended to be an exhaustive classification of all possible $R \& D$ fields or objectives but only to classify $R \& D$ fields and objectives that are either significantly active now or likely to become active soon in Australia; therefore, the absence of a field or objective should not be interpreted as that field or objective is unimportant.

The classification in final form may be published as The Australian and New Zealand Standard Research Classification which will also include codes specific to New Zealand, some of which are already included in this draft. (Bolding has been added)

The spreadsheet attached to the note showed what changes would be made. And, from the perspective of HET, the major change proposed was to drop from the Economics Discipline the classification grouping, 'History of Economic Thought and Economic History'. Only two sub-disciplines had been contained within this group: 'History of Economic Thought' and 'Economic History'. These two subdisciplines were to be taken from the Economics classification and placed under 'History, Archaeology, Religion and Philosophy' as a form of the History and Philosophy of Science. Thus, with both HET and EH no longer classified as part of economics, any studies undertaken in those areas would no longer be classified as representing economic research.

The remainder of this paper will deal only with the issues surrounding History of Economic Thought unless otherwise noted. But it should be kept in mind that there was a parallel campaign organised by economic historians, which also sought a review of the proposals that had been brought forward by the ABS.

\section{Reason for the Proposed Change}

The reasons for the change, as presented in the letter quoted above, were quite obscure. In order to clarify the issues involved, one of the co-authors of this paper, Alex Millmow, wrote to David Brett, the officer in charge of the reclassification process at the ABS. The following letter was received in reply. In his letter, Dr Brett, on behalf of the ABS, wrote:

Dr. Millmow,

Thank you for your interest in the revision of the Australian Standard Research Classification. As we discussed over the phone, I will give an overview of the reasons for the proposed relocation and merger of History of Economic Thought.

The Australian Standard Research Classification comprises of three classifications: Type of Activity, Fields of Research (FOR) (formerly 
Research Fields, Courses and Disciplines (RFCD)), and Socio-Economic Objectives (SEO). These classifications serve different purposes.

- The Type of Activity classification categorises research as pure or strategic basic research, applied research or experimental development;

- The Fields of Research categorises research by the processes used, and;

- The Socio-Economic Objectives categorises research by the subject matter of the research.

During the early stages of the revision it was noted that the RFCD lacked consistency in the use of processes as a classification tool, consequently in the preliminary version of the FOR compiled prior to expert consultation a number of relocations were undertaken to improve this. One change was the relocation of codes relating to history or philosophy of specific subject areas to one location, in the then proposed History, Archaeology, Religion and Philosophy division. History of Economic Thought and Economic History were two codes that were included in this process.

Expert consultation for the Economics division was conducted through the Academy of Social Sciences, however we did not receive any response regarding this change during this process. The Academy of the Humanities, who managed the expert consultation relating to the history and philosophy of specific fields, recommended the two economics codes be merged into one code entitled "History and Philosophy of Economics".

The changes to History of Economic Thought are summarised in the following table:

\begin{tabular}{|l|l|l|}
\hline & \multicolumn{1}{|c|}{ RFCD 1998 } & \multicolumn{1}{c|}{ FOR 2008 } \\
\hline Division & Economics & $\begin{array}{l}\text { Philosophy, Religion } \\
\text { and Culture }\end{array}$ \\
\hline $\begin{array}{l}\text { Discipline (1998)/ } \\
\text { Group (2008) }\end{array}$ & $\begin{array}{l}\text { Economic History and History } \\
\text { of Economic Thought }\end{array}$ & $\begin{array}{l}\text { History and } \\
\text { Philosophy of Specific } \\
\text { Fields }\end{array}$ \\
\hline $\begin{array}{l}\text { Subject (1998)/ } \\
\text { Field (2008) }\end{array}$ & History of Economic Thought & $\begin{array}{l}\text { History and } \\
\text { Philosophy of } \\
\text { Economics }\end{array}$ \\
\hline
\end{tabular}

The reasons for the relocation and merger are as follows:

- Classification consistency with regards to the use of processes as the key driver of classification location.

This assumes that the processes used in History of Economic Thought are primarily historical and philosophical rather than economic. This is the critical issue from the perspective of a classification and a rule that has been widely applied throughout the classification, although there are some exceptions in the draft currently being circulated. These will be rectified in the next draft.

- Groups (formerly disciplines) which are not useful for describing either the breadth of R\&D or how spending is apportioned, were restructured. 
The discipline Economic History and History of Economic Thought only contained two codes, which is not sufficiently broad. It also represented only $1.2 \%$ of all public sector R\&D in economics in 2004 (the most recent data available), thus is too narrow to be useful for understanding where economics R\&D expenditure occurs.

- Low level of reported activity.

Less than $\$ 1 M$ of $R \& D$ expenditure was recorded against each of the codes for Economic History and History of Economic Thought in 2004, and the amounts have been declining across the surveys available to us. Both codes are above the level where we would consider deletion at this revision, however unless there is an upswing in recorded activity in these fields both would most probably be deleted at the next revision. The merger should ensure the future viability of a code describing these research areas for the medium term.

If this change is undesirable to your research community, we can contemplate undoing these changes on the following grounds:

- Evidence that R\&D activity is significantly underreported or anticipated to significantly increase in the near future (to effect a demerger)

$\circ$ Evidence that the assumption that History of Economic Thought R\&D primarily involves processes that are historical and philosophical is false (to effect a relocation to another division)

Should you argue for returning this field to Economics we will also require a suggested location within this division. The Economic History and History of Economic Thought group will not be reinstated, however we can consider a replacement for it.

I hope this information is of use to you. The email address for your members to send any comments to us is asrc.comments@abs.gov.au

Regards,

David Brett

\section{Justifications Given for the Proposed Change to the Classification System}

The three justifications for the proposed change, from the perspective of those involved in undertaking HET, were oddly chosen, as none of them seemed concerned with whether the HET was itself a study of economics and the economy. That seemed to make little difference. What was important instead was whether the techniques and methodologies were those used by economists and then, secondly, whether there was enough public expenditure on such research to be worth recording. What was not considered was whether such research was being undertaken at all or whether that research had merit. There was also, from the point of view of those who were devising the new classification system, the issue of whether the field code was sufficiently broad for its recording purposes. Thus, the three criteria listed by Dr Brett for removing HET from within the Economics discipline were: 
- "the processes used in History of Economic Thought are primarily historical and philosophical rather than economic"

- "less than $\$ 1 \mathrm{M}$ of R\&D expenditure was recorded against each of the codes for Economic History and History of Economic Thought in 2004, and the amounts have been declining across the surveys available to us"

- "the discipline Economic History and History of Economic Thought only contained two codes, which is not sufficiently broad."

Each of these issues will be discussed in turn.

\section{Processes of the History of Economic Thought}

The first of the issues raised is the only one that actually deals with the nature of the History of Economic Thought as a subject area. The aim of the ABS was to achieve 'classification consistency with regards to the use of processes as the key driver of classification location' (italics added). Underpinning this was a judgment made at some level on what it is that economists do, and based on that judgment, some assessment of the techniques and processes used by such economists in undertaking their tasks.

The core question raised by the ABS was thus whether historians of economics are economists first and historians second, or are, instead, historians, or perhaps even philosophers, first and then economists second, assuming that they are even economists at all.

The question was not whether one might have studied economic theory in undertaking one's research into some area in the history of economics, but whether even an economist in turning to HET is any longer either participating in the study and advancement of economic theory or is involved in the application of economic processes and techniques in answering some economically relevant question.

To complicate matters, even economists untrained in and unfamiliar with the history of economics are less likely to understand the work and importance of HET in both the advancement of economic theory and the development of economic policy. But, for an historian of economics, and for many other economists as well, studies in the historical development of economic theory are up-to-the-minute in their relevance for the crafting of theory and in the formulation of policy in the here and now. Thinking through an early nineteenth century debate would sharpen an economist's understanding of contemporary issues in a way that would not occur if a modern physicist were to read the debates on physics that were taking place at the same time in the distant past.

The most obvious example of the importance attached to the history of thought in refining an economist's ideas can be seen in the literature search requirement at the start of virtually every doctorate in economics. $\mathrm{PhD}$ candidates begin their thesis with an in-depth discussion and analysis of previous work in the subject area. In part it is to ensure that the student is aware of past work in the area and in part it is to ensure that nothing of significance is ignored. But, most importantly, the reason for the literature search is to compel students to internalise the major debates in their field of study so that the actual contours and nuances of current textbook theory are properly understood. One cannot go forward in economics, it is widely if not universally understood, unless one has made sense of the past. 
HET provides orientation and framework. It provides depth and ballast to the concepts that reach textbook level. Knowing the circumstances in which different theories were developed, the surrounding debates that took place at the time and the contrast between the conclusions that were ultimately accepted as opposed to the ones which were not, provides a context in which to understand the generally accepted theoretical approach. Indeed, the very way in which the losing sides in so many of these controversies continue to contest the field provides an important part of the ongoing debate within economics. This is part of the role played by HET within economic theory.

HET is not a form of the history and philosophy of science but is an integral part of economics. The study of the history of economic theory allows economics to understand itself. Without HET, economic theory is a lesser subject, barren of direction and lacking in depth.

\section{$5 \quad$ Useful Description of Activity}

Beyond the subject matter itself, the ABS raised two additional issues which were related to the classification structure rather than to the relevance of history of economics as an area of study. The first of these, as stated by Dr Brett, was that 'the discipline Economic History and History of Economic Thought only contained two codes, which is not sufficiently broad'.

This was restated in a much more emphatic form at the end of the letter where Dr Brett wrote, 'the Economic History and History of Economic Thought group will not be reinstated, however we can consider a replacement for it'. It was this particular statement that did much to create a great deal of alarm within the HET community as it was taken to mean that under no circumstances would the History of Economic Thought be allowed to remain a sub-discipline within Economics.

Upon clarification, it turned out that this was a statement relating to the ABS's view of the appropriate number of members in a grouping within the classification system. In the old classification system being replaced, within the discipline of Economics the group, 'History of Economic Thought and Economic History' contained only two members, 'History of Economic Thought' and 'Economic History'. A group with only two members was, rightly or wrongly, considered too small by the Bureau. The aim therefore was to remove this grouping. This did not, of itself, indicate that HET ought to be deleted from the Economics discipline, because, as noted by Dr Brett, the ABS 'can consider a replacement for it'. This issue was not the insuperable barrier the text of the letter had indicated.

\section{Level of Public R\&D Expenditure}

The second matter related to the classification structure itself rather than to the subject matter of HET and was the question of the level of public funding for historians of economics and economic historians. Here the issue was whether the small level of public funding received by historians of economics would justify having a separate category for the History of Economic Thought in the classification system. As noted in the letter from Dr Brett:

The discipline Economic History and History of Economic Thought ... represented only $1.2 \%$ of all public sector R\&D in economics in 2004 (the most recent data available), thus is too narrow to be useful for understanding where economics R\&D expenditure occurs. 
He also wrote:

Less than $\$ 1 M$ of $R \& D$ expenditure was recorded against each of the codes for Economic History and History of Economic Thought in 2004, and the amounts have been declining across the surveys available to us. Both codes are above the level where we would consider deletion at this revision, however unless there is an upswing in recorded activity in these fields both would most probably be deleted at the next revision.

HET is not a subject area that one would expect to require high levels of public support. Lone researchers working with archival material is the standard. There are no expensive forms of apparatus, few data sources to buy in and seldom a need to employ research assistants. Relative to other forms of study, especially in the natural sciences but even amongst economists, historians of economics cannot be expected to require high levels of public funding.

It was this particular form of metric that was at the heart of the problem from the point of view of those designing the classification system. It was not even that research was not being undertaken; it was that the research did not require high levels of public funding.

Yet absolutely nothing in relation to the value of the research undertaken is revealed by the amount of public funds expended. The conceptual basis for using the level of public funds expended as a measure of value is, as every economist would understand, deeply flawed

Nevertheless, this is a genuine problem. The ABS is reluctant to include as a category in its classification system a sub-discipline in which there is only a limited level of expenditure. This is not a judgment on the worth of HET, only a view that it does not wish to populate its statistical tables with data points with only a negligible level of expenditure recorded.

Yet, if this is a problem for the inclusion of the History of Economic Thought within the Economics Discipline, then it would have been just as much a problem for its inclusion as History and Philosophy of Economics within History, Archaeology, Religion and Philosophy. This, too, the ABS had noted, where Dr Brett has written about HET and EH, that 'unless there is an upswing in recorded activity in these fields both would most probably be deleted at the next revision'.

Even with the ABS having determined that HET and EH are to be retained, an issue discussed in further detail below, the low level of recorded public sector expenditure will continue to make the History of Economic Thought vulnerable in future classification reviews. And this is not an issue of placement within the classification system, but whether HET ought to be included at all.

\section{$7 \quad$ Response to the ABS Proposed Reclassification}

From the moment that the notice was sent out to HETSA members by John Lodewijks there was a spontaneous grouping formed within the HETSA membership who took it upon themselves to attempt to reverse the ABS's initial decision. The five names, recorded for posterity, were, in alphabetical order:

- Tony Aspromourgos (University of Sydney)

- William Coleman (ANU)

- Steven Kates (RMIT University)

- John Lodewijks (University of Western Sydney)

- Alex Millmow (University of Ballarat) 
They became the inner or 'war' cabinet and organised the various approaches and actions taken. No meetings amongst the five occurred, as all exchanges were co-ordinated via an email system directed through John Lodewijks. A more extended email system that incorporated the majority of HETSA members was also enlisted not just to keep the wider membership informed but also to ensure that all thoughts on how to deal with the various issues could be carefully considered.

The major initiatives undertaken by this inner group included:

- alerting the HETSA membership and encouraging submissions (JL)

- posting a notice on the international HES website outlining the ABS proposal to reclassify HET inviting overseas historians of economics to respond (JL)

- contacting prominent economists in Australia to seek their support (AM, SK)

- publication of articles within the Australian media (SK)

- publication of articles on media websites (AM)

- direct contact with the ABS (AM, WC, JL, SK)

- speaking to the Academy of Social Sciences (AM)

- personal meeting with the ABS (SK).

There was a strong response from the HETSA membership. All members were asked to provide their own response to the ABS's initial decision, an approach which proved to be very effective. Rather than it being one official submission containing the homogenised views of the entire membership, the ABS received instead the individual views of a large number of historians of economics, each of whom had expressed their own concerns in their own words. This decentralised approach turned out to be very effective.

The arguments put by the individual submissions of individual HETSA members was underscored by important statements of support from economists both in Australia and from those across the world. Domestically, strong support for retaining the history of economics within economics came from the following individuals, amongst many others:

- the President of the Economic Society of Australia

- the President of the Economic History Society of Australia and New Zealand

- the CEO of the History of Economic Thought Society of Australia

- the Secretary of the Department of Prime Minister and Cabinet

- the Chairman of the Productivity Commission

- the Chief Executive Officer of Universities Australia

- the Executive Director of the Academy of the Social Sciences in Australia

- a former Governor of the Reserve Bank of Australia

- a former Australian Statistician

- the editors of the History of Economics Review

- a number of Australian Research Council Federation Fellows.

Internationally, there was a flood of support, which included a letter from the 2006 Nobel Prize winner in Economics, Professor Edmund Phelps. In addition, there were statements of support from a number of associations of economists, especially from amongst associations of our fellow historians of economic thought: 
- the President of the Royal Economic Society in the UK

- the Chair of the Economics section of the British Academy

- the President of the (British) Economic History Society

- the President of the (North American) History of Economics Society

- the President of the Italian Association for the History of Political Economy

- the Board of the Society for the History of Economic Thought, Japan

- 30 Members of the Greek Society for the History of Economic Thought.

This phenomenal level of support both national and international was instrumental, probably crucial, in reversing the decision made by the ABS. It was clear from the letters sent that amongst economists there was perfect clarity that History of Economic Thought and Economic History were integral parts of economics itself. And certainly if economists believe this to be true, no outside body, with its necessarily limited understanding of the processes of economics and the work of economists, should be in a position to say anything else.

\section{$8 \quad$ Social Sciences Classifications Review Process}

Yet in spite of the strong support from the economic profession itself, there was far less support from amongst social sciences generally. Most importantly, the Academy of Social Sciences, which was directly involved with the classifications review process, did not contact representatives of historians of economics or economic historians although both have representative bodies, nor did the Academy recognise the problematic nature of the changes they were prepared to endorse.

In a letter to one of the authors [AM] from Tim Sealey of Universities Australia, a member of the classifications review committee, it was made clear that he was in full agreement with the ABS's initial proposal. He made the following arguments in support of the proposed change. These are considerations that the HET community will need to reflect on.

- HET is an unimportant field of study.

- the classification system should not be seen as a means to provide recognition to unimportant fields of study - importance being determined by how much public money is being received.

- the amount of money spent on HET is low and is likely to fall in future.

- removing HET from the economics discipline will have no effect on the standing of historians of economics within the university system nor on their position within the RQF system nor on the level of public funding they receive.

- the classification system needs to be restructured so that valid international comparisons can be made.

- moving all fields of study with the word 'history' in its title to the History category would help simplify the classification system and make it more precise.

The most important of the issues raised by Sealey related to the value of the study of the history of economics. In stating in respect of HET that 'there has to be greater alignment between research activity and Socio-economic objectives' the clear message was that the activities of HET are not seen as adding anything much 
to the sum total of useful human knowledge. Removing studies in the history of economics from the discipline of economics itself was therefore viewed as a matter of not much academic consequence. The lack of funding, the simplicity of the classification system or international comparability were all ancillary to this one core question.

This is not the place to answer all of these issues, although a start was made in our response to matters raised by the ABS. But it is one thing for the ABS to wish to simplify its recording system; it is quite another when other academics fail to understand the significance and role of the study of the history of economic thought. The following statement from Sealey's letters indicates the breadth of the opposition to the retention of HET within economics:

'The revisions to the RFCD and the SEO proposed by the ABS

in consultation with the whole sector (not just universities) would appear to be the most appropriate course of action in terms of simplification and consistency of terminology.'

The decision was thus not just a decision of a statistical bureau but represented 'the whole sector (not just universities)'. Who it might be that is encompassed within the category 'the whole sector' is hard to gauge but the clear implication is that it went well beyond the universities themselves to encompass the wider field of all those with an interest in education and research. Re-examination of the relationship of historians of economics with other economists, with the social sciences in general and others beyond the academic world is clearly a high priority for those of us involved in the study of the history of economics.

\section{The Parallel Approach of the Economic Historians}

It is a remarkable fact that much of what has been described as the reaction of historians of economics was paralleled by economic historians without any coordination of our individual efforts. Attempts from within the HET community to make contact early on came to nothing and it was only very late in the process that it became apparent that the economic historians had commenced their own lobbying effort in almost exactly the same way as was undertaken within HET.

That both groups reacted in the same way does provide support for the view that amongst their practitioners, both of the 'histories' recognised themselves as part of economics so that the proposed changes were seen as totally inappropriate. While for others looking for a more orderly classification system in which anything labelled 'history' is put under the history heading, those in both fields saw themselves as economists doing economic work. The instantaneous reaction at the implication that these areas are actually history rather than economics makes a profound statement about the actual nature of both areas of study.

Moreover, the separate approach of the two histories in dealing with the ABS was itself a strong indication that the word 'history' makes a very poor agent for grouping. The perspective of those who had devised the original system - where history of economics and economic history were bundled together under a single grouping - was that they were in some sense similar in some vaguely defined way. Yet the fact that when all hands were called to man the pump, it turned out that there was virtually no overlap in membership between the specialists in the two areas. One was either a historian of economics or an economic historian but in no case was anyone both. 
And indeed, that is precisely the case. The two subject areas deal with separate matters and in separate ways. Moreover, it is because of the differences in the two that the history of economics was from the start under greater risk. Since the issue was the 'processes' that were used, economic historians could easily be seen as using the identical techniques to look at past events that other economists use to examine the economy in the present.

With historians of economics, however, the issues were more difficult and problematic. Amongst economists it is understood that a knowledge of the history of the subject is intrinsically part of how theory is advanced and policy is developed. There are, of course, historical studies within economics that are just narrative without any analytical significance. But that is only one part of HET, and not the most important.

Where the importance of HET lies is in the review of past terrain to examine the meaning of theories, their application and future direction. This is part of the 'processes' of economics but it is not one that would necessarily be understood by someone outside the field. It would have been a profound mistake to have removed history of economic thought from economics, but the concern is that few beyond the confines of economics would have understood why this was so, a problem that is of less significance to historians of economics.

\section{How the Classification Issue was Resolved}

The ABS, following the overwhelming response from historians of economics, which was paralleled by economic historians, agreed to review and reverse its earlier proposal. The following email from the Bureau was sent to those who had forwarded submissions opposing the proposed change:

'Your concerns with regard to the proposed treatment of Economic History and History of Economic Thought have been formally noted by the review team, and your submission and interest together with others on this issue has been taken into consideration. On the basis of the information received by the review team, the proposal with regards to these research fields has been revised. The revised proposal is to keep Economic History and History of Economic Thought within Economics. The revised proposal is based on extensive feedback on this issue and the core reasoning behind this proposal is as follows:

0 the techniques used in Economic History research are identical to those used in other areas of applied economics - the subject matter is historical economic data;

$\circ$ the History of Economic Thought can be described as being primarily concerned with the development of economic theory.

The current thinking is therefore to align these categories with the respective sub-categories of applied and theoretic economics.'

On 31 March 2008, the ABS released its final revised classification codes entirely in keeping with its previously emailed undertakings. The classification code 'History of Economic Thought and Economic History' had been removed. HET was placed within Economic Theory and EH was classified as part of Applied Economics. Economics is now classified as Division 14, which includes 'Group 1401 Economic Theory. In relation to this group, the ABS classification code now 
states specifically that the history of economic thought is in this group. This is the relevant statement from the ABS's Revised Research Classification Code:

'This group covers economic theory. It includes history of economic thought. This group has five fields:

\section{History of Economic Thought \\ 140102 Macroeconomic Theory \\ 140103 Mathematical Economics \\ 140104 Microeconomic Theory \\ 140199 Economic Theory not elsewhere classified.'}

Should it be thought that the placement of history of economic thought as first in this listing reflects any judgment on the subject matter itself, it should be noted that the classification list is merely in alphabetical order.

It is then noted by the ABS under the heading 'Exclusions' that 'history and philosophy of economics is included in Group 2202 History and Philosophy of Specific Fields'. But, should one actually follow the pathway to Group 2202, all one finds are eleven different subject codes representing the histories of vast areas of the academic world. Had HETSA not taken the steps it took, History of Economic Thought would have been utterly lost, placed under Grouping 220208 'History and Philosophy of the Social Sciences'. As a subject area, history of economic thought would have completely disappeared.

In many ways it is regrettable that the ABS was adamant that it would not retain a separate division containing just HET and EH. But that is a much lesser matter than the near-miss disaster that was about to occur had history of thought and economic history been hived off into some far region in the nether world of academic obscurity. This was a fight in which it turns out HET and EH had even more to lose than was ever fully understood at the time. History of economic thought and economic history are not separate from economics; they are as much a part of economics as microeconomic theory and international trade and it is absolutely right that this understanding is now to be embedded in the Standard Research Classification Codes.

There is no doubt that had the proposed change been made it would have diminished economics as a subject within Australia and the standing of Australian economists overseas. There is also no doubt that the outcome that the ABS has now proposed is appropriate, as the testimony from so many economists from across the world has so eloquently shown. But none of this is to deny just how close run this entire episode has been. Nor does any of this foreclose on the possibility that this same threat may recur when the classification system is next revised. But that will be for another generation of historians of economics to deal with should this issue ever arise again.

\section{Future Action}

There are a number of lessons that can be taken away from this episode that ought to be the basis for action.

Historians of economics should make it more clearly understood what role the study of the history of economic thought plays.

Studying the history of economics is an integral part of the process in which economic theory is both learned and developed. The sad fact is that even many 
economists do not understand this, so it should not be surprising that this is not at all understood within the wider academic community. But economics is not a timeless body of conclusions that arose from nowhere; it is, instead, a series of integrated theories that evolved from the existing theories of the time and which grew out of particular circumstances in answer to specific problems.

The historical context of the development of theory is to this day an identifiable aspect of the teaching process, particularly in macroeconomics, where various approaches are routinely labelled according to their historic origins (for example, Keynesian, classical, Ricardian and others). It is also routine to instruct economists in relation to historic disputes between economic schools. The examples of Keynes versus the classics in one era followed by Keynesians versus the monetarists in another is known by every student of economics. That these remain live debates makes it all the more important that there be recognition of the way in which the history of the subject affects the choice of economic theories. Economic theory is path dependent.

At a minimum, HET should seek to play a larger role within the mainstream of economics. Attendance at conferences of economists should be encouraged and HET sections should be routinely incorporated into the annual Australian Conference of Economists.

Historians of economics should take steps to ensure that there is wider recognition amongst economists that HET is a very productive means of learning the tools of the economist trade.

All economists must learn basic theory and most will learn mathematical techniques along with statistics and econometrics. The next steps taken are studies of the sub-disciplines of economics, amongst which is the history of economics. Studies in every area of economics are vastly deepened by the study of the history of the relevant theory. Moreover, it is also true that a study of the relevant theory deepens one's understanding of any area of economics. An applied economist whose background is in HET is the match of any other economist with a background in one of the other specific fields of study.

It might also be noted that people who have written some of the most profound works of economic theory have also written masterworks in HET, Karl Marx and Joseph Schumpeter being two of the most notable. The value of HET as a means of understanding practical economic issues needs to be more widely appreciated.

Historians of economics need to take steps to ensure that the views of the HET community are properly represented on decision-making bodies that can affect the future of the subject.

It was mere chance that HETSA members were alerted to the impending change in the underlying classification system. A delay of two weeks and the timeframe in which to reverse the decision might have passed. There was a complacency that others would understand the role of the history of economics. It would have been almost inconceivable, until the proposal was actually released, that others might have taken the view that they did.

Historians of economics will therefore need to be more vigilant. It is now evident that HET is not highly regarded by others whom we might have expected to look after our interests. Ensuring that such decisions cannot be made without our 
society being consulted must become a high priority. Consideration needs to be given to how historians of economics can become involved in such decisionmaking bodies.

History of Economic Thought and Economic History should forge a closer relationship if not so much in subject matter but in a mutual protection compact.

History of Economic Thought and Economic History are two separate subjects brought together by the use of the word 'history'. Both look back to the past, in the first to examine the development of economic theory through time, in the latter through the application of economic tools to understand the development of industries, regions, nation states and indeed the entire world. There is thus little in common so far as their subject matter is concerned.

But where there is a serious overlap is in the general lack of understanding of the nature of the research undertaken and the value of the activities of researchers in each subject area both to economics itself and to the wider community. The reaction of Universities Australia is only one example of the lack of understanding that is currently prevalent. It is a problem that is unlikely to disappear and is, in fact, one that might well worsen given how specialised the different research fields have become.

It should therefore become a high priority for the executive of HETSA and the relevant body representing economic historians in Australia to meet formally and set up some form of institutional structure to look after our collective interests since it is absolutely clear that no one else can be counted on to do so.

The structure put in place should be constituted by a formal agreement to meet at least annually, probably at the meetings of each of our societies in alternate years. There should be a formal agenda for these meetings, the first one of which being any perceptions of threats to the standing of our subject areas.

There is an attitude that once an immediate danger has passed there is no further reason to guard against some future occurrence. Prudence would, however, dictate precisely the opposite conclusion. We have been warned about the attitudes of others in positions of authority beyond our own subject areas. To quote Benjamin Franklin, 'we will all hang together or we will hang separately'. This should become a high priority matter for both societies.

The executive of HETSA needs to be expanded so that a larger body of individuals is given the responsibility for looking after the affairs of the membership.

HETSA has contented itself with an executive that consists of a single officebearer. There is a Chief Executive Officer who acts as treasurer as well. As we have discovered, there are occasions when a single person cannot deal with the flow of events. It was a problem, for example, that one of the authors of this paper [SK], although writing a submission and meeting with the ABS to negotiate an outcome, nevertheless did so without any official standing within the Society.

A larger board structure - made up, perhaps, of a Chief Executive Officer, the immediate past CEO, a deputy CEO, Secretary, Treasurer and two or three members of the executive - would provide a more appropriate structure for handling such issues. In this instance, an ad hoc committee more or less formed itself, comprising individuals with the inclination to take this problem on. A more 
formal structure would ensure that a wider grouping would be involved in attending to the affairs of the Society at large. An amendment to the society's constitution to permit such an expansion of the executive may be required.

* School of Economics, Finance and Marketing, RMIT University, GPO 2476V, Melbourne Vic 3001, and Australian Productivity Commission. Email: steve.kates@rmit.edu.au.

** School of Business, Post Box 663, University of Ballarat, Ballarat Vic 3353, Australia. Email: a.millmow@ballarat.edu.au.

\section{Notes}

1 Steven Kates is Senior Lecturer in Economics at RMIT University in Melbourne and a Commissioner on the Australian Productivity Commission. Alex Millmow is Senior Lecturer in Economics at the University of Ballarat and President of the History of Economic Thought Society of Australia.

2 HETSA stands, of course, for the History of Economic Thought Society of Australia, mentioned here in full only because there may come a day when the society may take on another name, as does happen to associations from time to time, and thereby rendering the elements of the acronym unknown. At the moment, though, it is assumed that all readers of this journal will know what these initials mean. 